\title{
An outcome analysis of intertrochanteric fracture of femur managed with proximal femoral nail antirotation II
}

\author{
Hemeshwar Harshwardhan, Shubhanshu Jain*, Manish Sharma
}

Department of Orthopaedics, J.L.N. Medical College, Ajmer, Rajasthan, India

Received: 16 March 2019

Revised: 30 May 2019

Accepted: 01 June 2019

\section{*Correspondence:}

Dr. Shubhanshu Jain,

E-mail: shubhanshu.jainn@gmail.com

Copyright: (c) the author(s), publisher and licensee Medip Academy. This is an open-access article distributed under the terms of the Creative Commons Attribution Non-Commercial License, which permits unrestricted non-commercial use, distribution, and reproduction in any medium, provided the original work is properly cited.

\begin{abstract}
Background: Intertrochanteric fractures are common osteoporotic fractures in adults above 60 years with high mortality and morbidity. Common techniques for fixation of these fractures are sliding hip screw and plate or intramedullary nailing. Intramedullary nailing has advantage of short incision, less operative time, rapid rehabilition $\&$ thus decreased medical complications. PFNA II is newer intramedullary implant developed to obtain better fixation strength in osteoporotic bones. Biomechanical studies has demonstrated that PFNA II blade has a significance of higher cut out resistance than other commonly used screw systems.

Methods: Prospective follow up study carried out at J.L.N. Medical College Ajmer from 1 March 2017 to 31 st October 2018. 30 patients with unstable intertrochanteric fractures were included and operated on fracture table in supine position with PFNA2. We measured operative time, duration of hospital stay, modified Harris hip score and complications.

Results: The mean age of the patients was 70.83 years of age. The mean time in surgery was 38.2 minutes. The mean amount of blood loss in surgery was $110.8 \mathrm{ml}$. In implant related complications, 2 patients had cut out and 1 patient had pull - out of the implant. Functional results according to modified Harris hip scores was found to be excellent in 8 $(30 \%)$ patients, good in $12(40 \%)$ patients, fair in $7(20 \%)$ patients and poor in $3(10 \%)$ patients.

Conclusions: Elderly patients treated with PFNA2 has good outcome as less operative time, minimal blood loss, early weight bearing, less union time and very few cases of medial penetration and back out of spiral blade.
\end{abstract}

Keywords: Intertrochanteric, Intramedullary, PFNA II, Nailing

\section{INTRODUCTION}

Intertrochanteric fractures commonly occur in elderly patients with osteoporosis and its incidence will continue to rise due to the increasing life expectancy. The main aim of surgery is to mobilize the patient early. It is crucial to use an implant that is minimally invasive, allows early weight bearing, and has low complication rates. ${ }^{1,2}$

The types of implant used in these fractures have been divided into extramedullary implants and intramedullary nails. The choice of implant is mainly determined by the fracture pattern (stable or unstable). Unstable intertrochanteric fractures are those with major disruption of the posteromedial cortex because of comminution or are fractures with reverse oblique patterns or fractures with subtrochanteric extension. Fractures without posteromedial cortex disruption or subtrochanteric extension are considered stable. ${ }^{3,4}$

Several clinical and biomechanical studies have analysed the results of different implants such as the dynamic hip screw (DHS), the Gamma nail (GN) and the proximal femoral nail (PFN). Those devices have suffered a variety 
of complications like cut-out, screw back out, implant breakage, femoral shaft fractures and subsequent loss of reduction. ${ }^{5-8}$

PFN has some demerits like implant failure, screw cut out and screw migration which is also called $\mathrm{z}$ effect. In this $\mathrm{Z}$ effect proximal screw (de-rotation screw) of PFN migrate medially and distal screws (lag screw) migrate backward, while in reverse $\mathrm{Z}$ effect proximal screw (derotation screw) migrate laterally and distal (lag screw) migrate medially. Intramedullary nailing has advantage of short incision, less operative time, rapid rehabilition and thus decreased medical complications.

PFNA II is newer intramedullary implant developed to obtain better fixation strength in osteoporotic bones. Biomechanical studies has demonstrated that PFNA II blade has a significance of higher cut out resistance than other commonly used screw systems. ${ }^{9}$

\section{METHODS}

\section{Source of data}

This study was conducted in the Department of Orthopaedics, JLN Medical College \& Hospital, Ajmer, during the period 1March 2017 to 31 October 2018 and were treated surgically using PFNA II for patients who were diagnosed with unstable intertrochanteric fracture femur.

\section{Inclusion criteria}

Inclusion criteria were closed unstable inter trochanteric fracture (AO TYPE31A2\&31A3); ability to walk independently (walking aids are allowed) prior to injury.

\section{Exclusion criteria}

Exclusion criteria were open fracture; subtrochanteric fracture; intracapsular fracture neck of femur; pathological fracture; medically unfit patients.

The patients are taken up for surgery under spinal or epidural anaesthesia, positioned supine on fracture table, uninjured leg held in wide abduction. C- Arm image intensifier is positioned between patient's leg. Close reduction of fracture by manipulation is performed. Minimum 30 cases were studied. Patients were followed up for a minimum period of 6 months. With each follow up clinical and radiological evaluation was done.

\section{Statistical analysis}

Statistical analysis was done using SPSS Software (IBM Version-20).

\section{RESULTS}

In the study, all the patients were above 60 years of age. The mean age of the patients was 70.83 years $(>60$ years) of age. Around $40 \%$ of the patients were female and around $60 \%$ of the patients were male. $90 \%$ of the patients had sustained low velocity injuries due to fall on floor or trivial trauma whereas around $10 \%$ sustained injuries due to RTA. In present study left side is more involved around (60\%) than right side around (40\%). All fractures were classified according to the A.O. classification. 19 patients have AO type AO31A2 and 11 patients have type AO31A3 fractures (Table 1).

Table 1: Demographics and basic characteristics.

\begin{tabular}{|c|c|c|c|}
\hline \multicolumn{4}{|l|}{ Demographics } \\
\hline \multirow{2}{*}{ Age (years) } & $61-70$ & $71-80$ & $81-90$ \\
\hline & 16 & 9 & 5 \\
\hline \multirow{2}{*}{ Sex } & Male & \multicolumn{2}{|c|}{ Female } \\
\hline & 17 & \multicolumn{2}{|c|}{13} \\
\hline \multirow[t]{2}{*}{ Mode of injury } & $\begin{array}{l}\text { Low velocity } \\
\text { injury (Fall on } \\
\text { ground) }\end{array}$ & \multicolumn{2}{|c|}{$\begin{array}{l}\text { High velocity } \\
\text { injury (RTA) }\end{array}$} \\
\hline & 26 & \multicolumn{2}{|l|}{4} \\
\hline \multirow{2}{*}{ Side of injury } & Right & \multicolumn{2}{|l|}{ Left } \\
\hline & 16 & \multicolumn{2}{|l|}{14} \\
\hline \multirow{2}{*}{ Classification } & AO31A2 & \multicolumn{2}{|c|}{ AO31A3 } \\
\hline & 19 & \multicolumn{2}{|c|}{11} \\
\hline
\end{tabular}

Table 2: Operative details.

\begin{tabular}{|llll|}
\hline $\begin{array}{l}\text { Operative time (in } \\
\text { minutes) }\end{array}$ & $<40$ & $41-50$ & $>50$ \\
\cline { 2 - 4 } & 15 & 14 & 1 \\
\hline $\begin{array}{l}\text { Amount of blood loss } \\
\text { (ml) }\end{array}$ & $<100$ & $100-150$ & $>150$ \\
\cline { 2 - 4 } & 20 & 9 & 1 \\
\hline
\end{tabular}

Table 3: Complications.

\begin{tabular}{|c|c|c|}
\hline \multicolumn{3}{|c|}{ Complications } \\
\hline \multicolumn{3}{|c|}{ General complications } \\
\hline 1. & Decubitus ulcer & 1 \\
\hline 2. & Urinary tract infection & 0 \\
\hline 3. & Chest infection & 0 \\
\hline 4. & Deep vein thrombosis & 1 \\
\hline \multicolumn{3}{|c|}{ Local complications } \\
\hline 1. & Infection & 0 \\
\hline 2. & Implant break & 0 \\
\hline 3. & Cut out of the implant & 2 \\
\hline 4. & Pull out & 1 \\
\hline 5. & Shortening $(>2)$ & 0 \\
\hline 6. & Thermal necrosis & 0 \\
\hline 7. & Loss of reduction & 0 \\
\hline 8. & AVN hip & 0 \\
\hline
\end{tabular}


The mean time in surgery was 38.2 minutes (30 - 50 minutes). The mean amount of blood loss in surgery was $110.8 \mathrm{ml}(50-160 \mathrm{ml})$. It is measured by soaked gauge pieces. 21 patients have limb length shortening $\leq 1 \mathrm{~cm}, 9$ patients have shortening more than $1 \mathrm{~cm}$. Mean limb length shortening was $0.92 \mathrm{~cm} .15$ patients have radiological union time $\leq 14$ weeks, mean radiological union time was 12.23 weeks. In general complications one patient had decubitus ulcer \& one had deep vein thrombosis. In our study, we had screw pullout in 1 patient, 2 patient had cut out of the blade (Table 2 and 3).

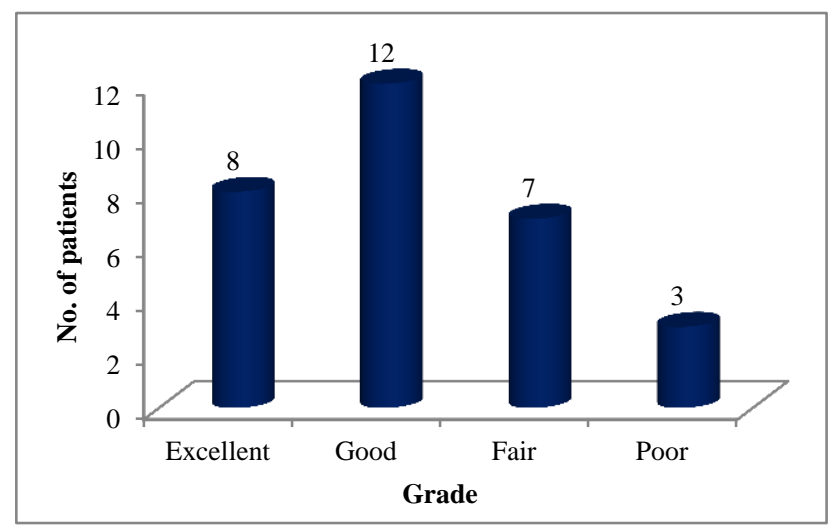

Figure 1: Final outcome measures (assessed with Harris hip score).

The functional status according to Harris hip score was excellent in $30 \%$, good in $40 \%$, fair in $20 \%$ cases and poor in $10 \%$ cases. Mean Harris hip score is 82.86 (Figure 1).

\section{DISCUSSION}

Stable fixation for trochanteric fractures is the goal of treatment. It allows early weight bearing and restoration of function. The PFNA2 device is a reliable intramedullary implant that can share a large axial load, its helical blade achieves an excellent fit through bone compaction with less bone removal. The inserted blade prevents rotation by locking with the nail and accordingly, it may be a more suitable implant for unstable trochanteric fractures especially in the presence of osteoporosis. Biomechanical studies have shown that the blade has a higher resistance to head collapse than commonly used screw design.

Mean time for doing PFNA2 was 43.1 minutes. The mean amount of blood loss for was $109.1 \mathrm{ml}$. The mean union time for inter-trochanteric fractures 13.5 weeks. Zeng et al found that PFNA use was associated with a significant reduction in duration of surgery, overall complication rate, post-operative fixation failure rate, and intraoperative blood loss as compared to PFN. ${ }^{10}$ Takigami et al also found that the surgical time and operative blood loss were lower with the use of PFNA as compared to PFN. ${ }^{11}$
Takigami et al found cut out rates of 2\%, Sahin et al found it to be $4.7 \%$ in their study. ${ }^{12}$ Mora et al recommend PFNA2 for treatment of trochanteric fractures in the elderly as its blade demonstrated a lower incidence of cut out in their study. ${ }^{13}$ Aguado - Maestro et al in their study of 200 patients treated with PFNA found that helical blade device reduced the rate of cut out \& accurate placement of helical blade was key factor to prevent mechanical failures. ${ }^{14}$

Table 4: Functional outcomes (as per Harris hip score system).

\begin{tabular}{|c|c|}
\hline Study & Mean Harris hip score \\
\hline Present study & 82.86 \\
\hline Liu et al ${ }^{15}$ & 84.00 \\
\hline Sahin et al ${ }^{12}$ & 77.8 \\
\hline Kashid et al $^{16}$ & 88.48 \\
\hline
\end{tabular}

The functional status according to Harris Hip score was excellent in $30 \%$, good in $40 \%$, fair in $20 \%$ and poor in $10 \%$ patients. Mean Harris hip score is 82.86 . According to Sahin et al the mean Harris hip score was 77.8. Harris hip scores were very good in 11 patients $(24.4 \%)$, good in 19 patients $(42.2 \%)$, moderate in nine patients $(20 \%)$, and poor in six patients $(13.3 \%)$. Liu et al in their study had mean Harris hip score 84.0. ${ }^{15}$ Kashid et al had Harris hip score of 88.48 (Table 4$){ }^{16}$

\section{CONCLUSION}

This study shows that use of the PFNA-II to treat intertrochanteric fractures in elderly patients has the following advantages: a simple operation, few complications, and good clinical efficacy. The time of clinical treatment of PFNA-II was relatively short, and the clinical samples observed in clinical treatment were relatively small; the long-term complications remain unclear. Therefore, large-sample, multicenter studies are required.

\section{Funding: No funding sources}

Conflict of interest: None declared

Ethical approval: The study was approved by the institutional ethics committee

\section{REFERENCES}

1. Lenich A, Fierlbeck J, Al-Munajjed A, Dendorfer S, Mai R, Füchtmeier B, et al. First clinical and biomechanical results of the Trochanteric Fixation Nail (TFN). Technol Health Care. 2006;14(45):403-9.

2. Strauss E, Frank J, Lee J, Kummer FJ, Tejwani N. Helical blade versus sliding hip screw for treatment of unstable intertrochanteric hip fractures: a biomechanical evaluation. Injury. 2006;37(10):9849.

3. Muller ME, Nazarian S, Koch P, Schatzker J. The comprehensive classification of fractures of long 
bones. 1st ed. Berlin, Heidelberg, Germany, New York, NY, USA: Springer-Verlag; 1990.

4. Orthopaedic Trauma Association Committee for Coding and Classification Fracture and dislocation compendium. J Orthop Trauma. 1996;10(Suppl. 1):1-154.

5. Liu M, Yang Z, Pei F, Huang F, Chen S, Xiang Z. A meta-analysis of the Gamma nail and dynamic hip screw in treating peritrochanteric fractures. Int Orthop. 2010;34(3):323-8.

6. Simmermacher RKJ, Bosch AM, Van Der Werken C. The AO/ASIF-proximal femoral nail (PFN): A new device for the treatment of unstable proximal femoral fractures. Injury. 1999;30(5):327-32.

7. Schipper IB, Bresina S, Wahl D, Linke B, Van Vugt $\mathrm{AB}$, Schneider E. Biomechanical evaluation of the proximal femoral nail. Clin Orthop Relat Res. 2002;(405):277-86.

8. Sommers MB, Roth C, Hall H, Kam BCC, Ehmke LW, Krieg JC, et al. A laboratory model to evaluate cutout resistance of implants for pertrochanteric fracture fixation. J Orthop Trauma. 2004;18(6):3618.

9. Penzkofer J, Mendel T, Bauer C, Brehme K: Treatment results of pertrochanteric and subtrochanteric femoral fractures: a retrospective comparison of PFN and PFNA. Unfallchirurg. 2009;112(8):699-705.

10. Zeng C, Wang YR, Wei J, Gao SG, Zhang FJ, Sun $Z Q$, et al. Treatment of trochanteric fractures with proximal femoral nail antirotation or dynamic hip screw systems: a meta-analysis. J Int Med Res. 2012;40(3):839-51.

11. Takigami I, Matsumoto K, Ohara A, Yamanaka K, Naganawa $T$, Ohashi $M$, et al. Treatment of trochanteric fractures with the proximal femoral nail antirotation (PFNA) nail system - report of early result. Bull NYU Hosp Jt Dis. 2008:66(4):276-9.

12. Sahin S, Ertürer E, Oztürk I, Toker S, Seçkin F, Akman. Radiographic and functional results of osteosynthesis using the proximal femoral nail antirotation (PFNA) in the treatment of unstable intertrochanteric femoral fractures. Acta Orthop Traumatol Turc. 2010;44(2):127-34.

13. Mora A, Marimon. PFNA in treatment of femoral fractures. Bone Joint $\mathrm{J}$ Orthop Proceedings. 2011;93(2):136.

14. Aguado-Maestro I, Escudero-Marcos R, GarciaGarcia JM, Alonso-Garcia N, Perez-Bermejo DD, Aguado-Hernandez HJ, et al. Results and complications ofpertrochanteric hip fractures using an intramedullary nail with a helical blade (proximal femoral nailantirotation) in 200 patients. Rev Esp Cir Ortop Traumatol. 2013;57:201-7.

15. Liu Y, Tao R, Liu F, Wang Y, Zhou Z, Cao Y, et al. Mid-term outcomes after intramedullary fixation of peritrochanteric femoral fractures using the new proximal femoral nail antirotation (PFNA). Injury. Elsevier Ltd; 2010;41(8):810-7.

16. Kashid MR, Gogia T, Prabhakara A, Jafri MA, Shaktawat DS, Shinde G. Comparative study between proximal femoral nail and proximal femoral nail antirotation in management of unstable trochanteric fractures. Int J Resorthop. 2016;2(4):354-8.

Cite this article as: Harshwardhan $\mathrm{H}$, Jain $\mathrm{S}$, Sharma M. An outcome analysis of intertrochanteric fracture of femur managed with proximal femoral nail antirotation II. Int J Res Orthop 2019;5:699-702. 